\title{
Putting Bling In The Classroom
}

Nicole Stegemann, University of Western Sydney, Australia

Catherine Sutton-Brady, University of Sydney, Australia

\begin{abstract}
This paper showcases the innovative use of a case study in action. It initially introduces a case study on the bottled water 'bling' and its phenomenal success in recent times. From a marketing educator's point of view it provides an example of how to bring reality to the class room and gives students hands on consumer experience through active learning. Details are provided on the inclass activity consisting of the case study, questions and guidelines for conducting the practiceorientated exercise. The paper concludes with student feedback on the activity, which highlights the level of student engagement and motivation to learning and class participation. It clearly shows that immersing students in the experience through active learning improves learning outcomes through concretisation of the concepts discussed in class. It also provides educators with recommendations for replicating this exercise.
\end{abstract}

\section{INTRODUCTION}

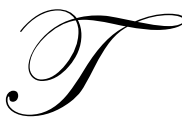

his paper showcases the use of an interactive class exercise in the form of a recreation of a water bottle label. Traditionally in marketing education, classes contain modules of lectures, analysis of written case studies and the textbooks' supplementary video clips. These modules are rather passive and don't require students' contribution. This paper takes an alternative approach to class exercises with a hands-on component in which all students participate and are encouraged to analyse a relevant marketing strategy with the use of various aids in the form of a product (water bottle Bling), newspaper articles, and a partial recreation of the production process.

The study reported in this paper took place over two semesters at an Australian university in the subject Brand and Product Management at undergraduate and postgraduate level. This subject is a compulsory subject for the students concerned. The subject focuses on the role of brand and product management in the context of planning and implementing marketing strategies and is intended to develop a critical appreciation of the inherent challenges contemporary firms encounter in creating and maintaining brand equity (UWS website). The subject covers a semester of thirteen weeks and by implementing the study over two semesters we were able to refine our approach and take student feedback into account. Within this subject a combination of different exercises are used however this paper deals specifically with the 'bling' exercise.

This paper begins with the rationale for this 'bling' acivity based on an investigation of the existing literature on the use of hands-on and reality based activities. Arising from the literature review we set the objectives for the exercise and look at the way in which we aimed to achieve these objectives. How the approach was implemented is explained in detail. Finally feedback from students is provided showing the success of activity in this subject.

\section{ACTIVE LEARNING}

We are constantly faced with the challenge business education of reality and relevance in the subject content and class activities we provide for students. Many researchers have worked hard to bring relevance and real life experience to the classroom (Sutton-Brady 2006; Elam and Spotts 2004; Kennedy, Lawton and Walker 2001; Razzouk, Seitz and Rizkallah 2003; Tabor 2005; Young 2002; Zych 1997).Others have said that hand-on experience in business education is crucial (Granitz 2001). While it is not always feasible to bring the students outside to see how things operate in the real world, authors have shown how active learning can in some way bring the reality into the classroom. Active learning moves away from the traditional lecture format which is purely 
passive and encourages students to become involved with the content (Hamer 2000). The assumption that lecturing equals learning is challenged with these active approaches and results have shown that active learning leads to increased student learning (Hamer 2000). McConnell et al, (2003) also found that students preferred active learning and that it promoted deeper understanding of course material and increased logical thinking skills.

Jakubowski (2003) reflects that students have expressed a strong interest in applying their classroom knowledge and many authors have shown how active learning can achieve this (McConnell et al 2003; Hamer 2000; Gremler et al 2000) Indeed Gremler et al (200) say that 'students must experience the class material and make it part of themselves' and that this does not occur 'when students simply listen to lectures, memorize information and take objective exams'. Active learning techniques can include semi-structured exercises that expect students to be critical and creative (Hamer 2000) and it was with these principles in mind that we developed the assessment task outlined below, we also had specific objectives in mind and these will now be outlined.

\section{SPECIFIC LEARNING OBJECTIVES}

We wanted something that would directly tie into the learning outcomes in this subject and through this active learning exercise felt we had found a way of linking hands-on experience with subject content and learning outcomes. The activity therefore aimed to:

- $\quad$ Create interactive learning exercises that keep students' interest, get them involved, create variety and therefore produce an exciting and engaging learning environment.

- $\quad$ Chose exercises that demonstrate real-life marketing cases that relate to students' interests and experiences. Pearce \& Sutton-Brady (2003) showed that students have to be actively familiar with the context in order to construct and build their own knowledge. This finding has also been supported by Dacko (2001) who demonstrated that individuals learn and understand best when situations are put into context they can see, listen, and read about. Providing them with different contexts and application of appropriate styles will enhance their understanding of questions.

- Increase students' level of motivation and engagement that should ultimately increase their learning outcomes.

\section{INTERACTIVE CLASS EXERCISE}

As discussed above literature shows that students positively respond to interactive and engaging class exercises. Therefore, we have developed different types of class exercises to develop students' interest and encourage critical thinking. Our 'bling' exercise encourages students to think about market trends and opportunities and to analyse and subsequently develop viable marketing strategies. This exercise relates to the bottled water market that has seen an increase in variety and extensive price increases. Examples of really expensive brands include blingh ${ }_{2} 0$, Love and Voss.

\section{WHY 'BLING'?}

Branded water is a growing phenomena today. In a recent newspaper article (Browne, 2008) Michael Mascha, a wine buff turned water aficionado is quoted as saying "Water is in a transition from being considered a commodity to being considered a product". This fact is obvious when we look at hotel and restaurant menus and see the prices now being charged for bottled water (see Table 1). Many restaurants and nightclubs now have very extensive water menus. This new branding challenge for water producers is one that we felt would resonate with our students. Sitting in class each day we see them drinking various brands of water so it is obviously something they are familiar with, although for many in a very different price category.

Our decision to use 'bling' was based on two main factors, firstly it is one of the most expensive brands on the market and secondly the design of the bottle with its 61 Swarovski crystals, allowed for its use in a hands-on exercise. 'bling' is the water of choice for many celebrities. Paris Hilton is reported to give it to her Chihuahua. It was developed by Kevin G. Boyd, a Hollywood writer-producer who observed celebrities treating their bottled water as a fashion accessory (www.tmz.com). It comes from English Mountain Spring in Tennessee and in the US retails 
at around US $\$ 55$ for the $375 \mathrm{ml}$ bottle (NYPostonline.com). Although many top nightclubs in Los Angeles charge up to US\$95. It comes in a cork sealed glazed glass bottle adorned with Swarovski crystals and that coupled with its celebrity status makes it fascinating to our students.

Table 1: Bottled Water Prices in Australian Restaurants

\begin{tabular}{|c|c|}
\hline Brand & Price in AUD\$ \\
\hline bling $\mathrm{h}_{2} \mathrm{O}$ & $\$ 85$ \\
\hline Hildon & $\$ 16$ \\
\hline Badoit & $\$ 15$ \\
\hline San Pellegrino & $\$ 12$ \\
\hline Antipodes & $\$ 16$ \\
\hline Springfield & $\$ 19$ \\
\hline Cloud Juice & $\$ 20$ \\
\hline Waiwera & $\$ 14$ \\
\hline Cape Grim & $\$ 18$ \\
\hline
\end{tabular}

Source: Adapted from "Turning Water into Wine" SH 3/08/08

\section{IMPLEMENTATION}

Two weeks before the exercise, students were asked to research the bottled water market. They were required to find relevant information such as news articles, websites, etc. as well as to visit various retail outlets that offer a wide range of bottled water. Their task was to compare the different product offerings and their respective marketing strategies. (This part is optional but has proven to engage students further in this exercise).

Students asked to prepare for this exercise, are encouraged to share their information and to provide their analysis of market opportunities at the beginning of the exercise. The lecturer also prepares various materials such as news articles, websites and a range of bottled waters. ${ }^{1}$ Our key product as pointed out earlier is the water called 'bling'2 - a 375ml handmade glass bottle with Swarovski crystals, which was purchased for 29 Euros at the fine food store 'La Grande Epicerie' ${ }^{3}$ in Paris.

We ask students various introductory questions such as:

- Have you seen or heard of the product before?

- Do you think the product is relevant and attractive?

- What do you think is its price point? Justify your answer

- After telling them the price we ask them whether they perceive the price tag as justified.

We then provide students with further information such as:

- Website for the product 'bling'

- $\quad$ Newspaper articles

- $\quad$ Competitive products such as Love and Voss

1 Browne, Rachel (2008), Turning water into wine, The Sun Herald, 3 August.

http://www.mecho.com.au/lifestyle/drinks/voss-artesian-bottle-water-norway-luxury

http://www.blingh2o.com

http://www.lovelimitededition.com

http://www.vosswater.com

2 http://www.blingh2o.com

3 http://www.lagrandeepicerie.fr 


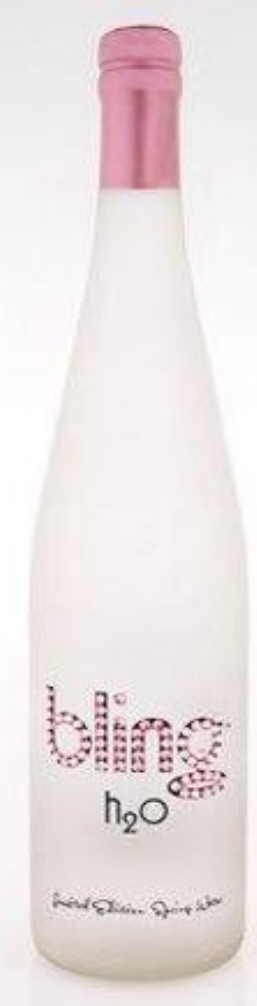

INSTRUCTION SLIDE

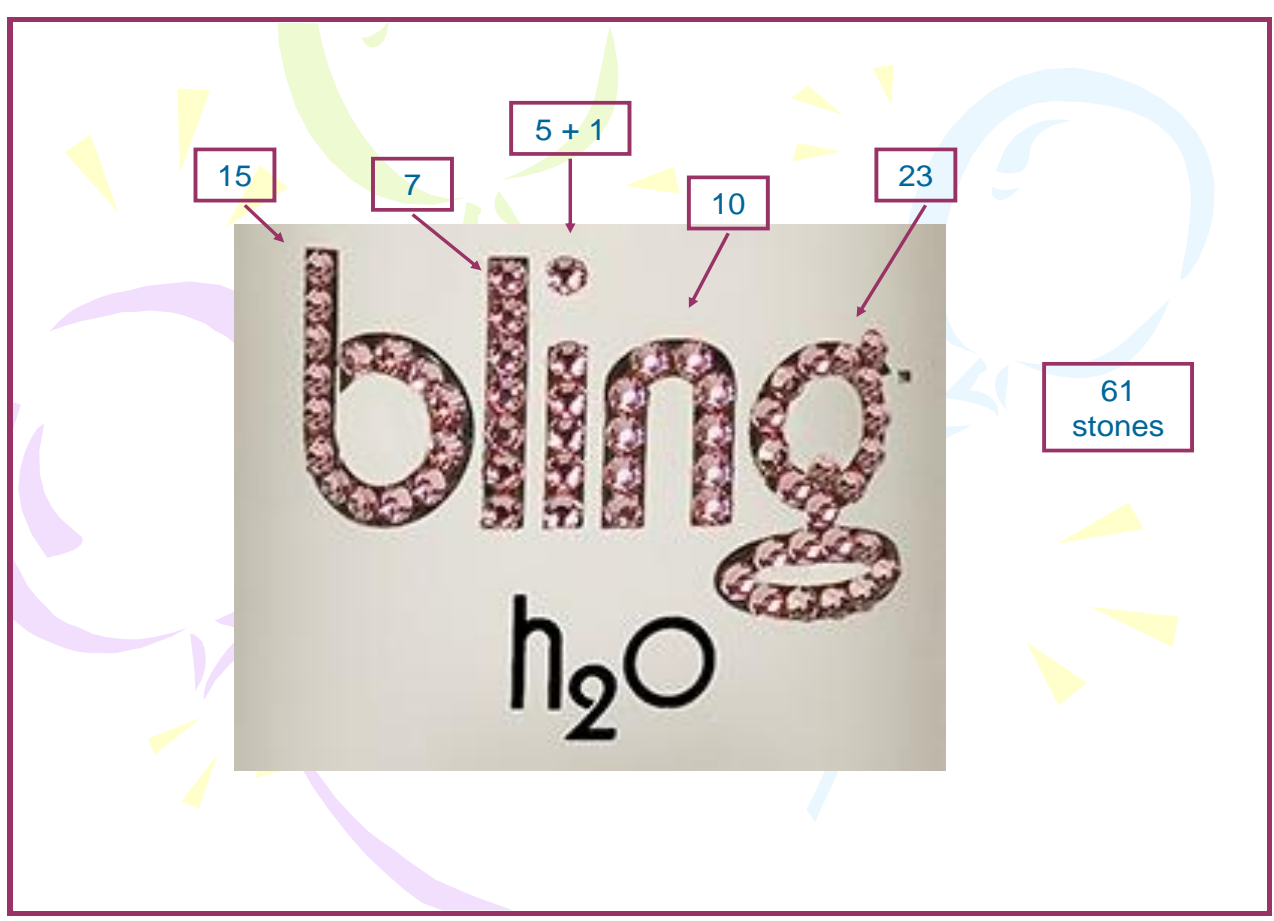


After examining the information provided above, students usually perceive the product as overpriced. To help them understand the part of the pricing strategy for the product, we introduce them to the production process of the product and ask them to recreate the label by way of a competition as described below.

\section{INTERACTIVE AND HANDS-ON APPROACH:}

- In pairs you are required to recreate the label of the water bottle 'bling' as shown on the slide. You will receive 61 crystals a choice of art papers, glue and scissors.

- $\quad$ You will be measured on speed and accuracy

This exercise usually takes about 15 minutes. During the competition we take pictures, which we make available for download on the subject support website. Once everyone has completed the exercise we ask students to reconsider the marketing strategy:

- What is the unique selling proposition of this brand?

- What product and non-product related benefits are communicated?

- What are consumers' purchase motivations?

- How would you evaluate the brand's overall marketing strategy?

- What pricing strategy has been chosen? Do you think that the company priced their bottled water correctly?

Students commonly have changed their perception regarding the value provided and the price point. However, they tend to disagree with the company's marketing strategy and don't consider their marketing communications efforts as adequate, and they make recommendations as how to redesign the marketing strategy in place.

\section{FINDINGS: \\ STUDENT FEEDBACK, MOTIVATION, LEARNING OUTCOMES, LEARNING EXPERIENCE}

To assess the effectiveness of our innovative approach we asked students for informal feedback, which was provided on paper, emails and through discussions. We felt since this was a new way of teaching it was crucial for us to validate its effectiveness and attractiveness. We received a great deal of feedback, most of which was enormously positive. Some students were initially skeptical about this exercise and its purpose, but were won over during its process. The following discussion will highlight our findings and the feedback specifically in relation to our original objectives.

All students participated in this exercise and were encouraged to evaluate the company's marketing strategy. They enthusiastically participated in this exercise and tried their best to replicate the label. They found it interesting and entertaining. Some of the students' comments included:

"it was fun to do the exercise"

"this was different, haven't done anything like this before"

"really like the competition and have sent the pictures to my friends"

"different way of teaching, really cool"

From our perspective, student participation was much greater compared to other exercises like written case studies or textbook related video clips. The students were very interested in lifestyle products and everything that appears to be trendy and different. Hence, they could easily relate to the chosen example and perceived themselves as potential consumers. While doing the exercise they enthusiastically chatted about the product and were keen to share their thoughts and perceptions with their classmates. It was interesting to see how seriously the students took this competition and really tried their best to achieve a close reproduction of the label. Their responses were well thought through and logically supported and justified. 


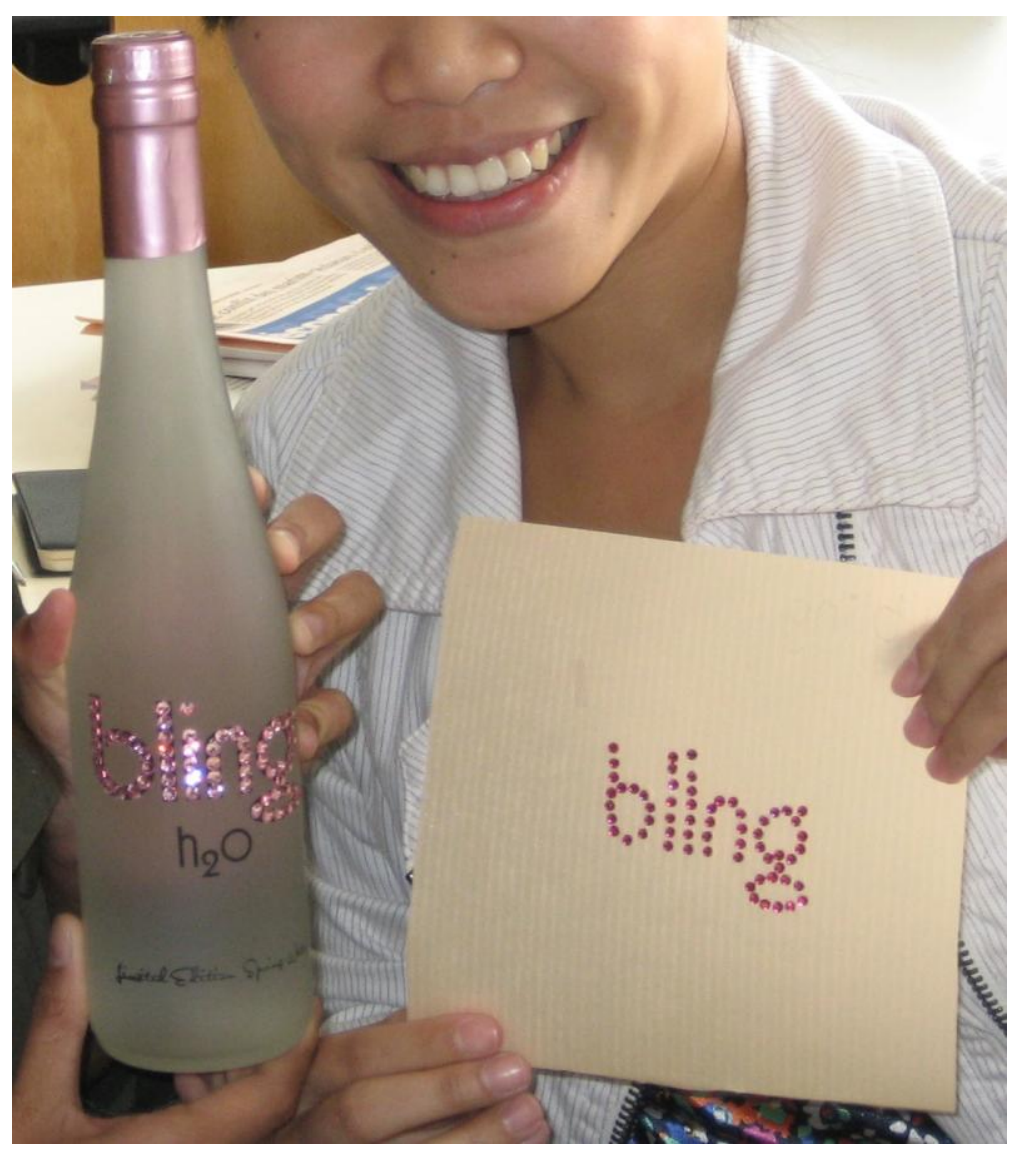

We achieved a fun working environment that was educational but also relaxed and entertaining. We noticed that the class environment and level of communication between students greatly improved when using a hands-on, active learning exercise - it felt like the students actually enjoyed coming to class and were curious to see what they were presented with in each class.

We compared the exam results for various semesters - those in which we didn't use this active learning approach with the ones we did - and noticed that students performed better when exposed to interactive exercises. This outcome has also been shown by other authors who explain the use of active learning techniques where students who are immersed in the content will have a better understanding of the subject matter; and as they actively participate in the exercises find it easier to provide well-thought through answers - learning by doing (Hamer 2000; McConnell et al. 2003).

\section{CONCLUSION}

Our findings overall are very positive and do as pointed out fit with the findings of others in the area of active learning. Students are encouraged to a deeper understanding of the strategies in marketing and also see the relevance of what they are learning. The connection with reality is vital in promoting improved learning outcomes. We have outlined the implementation of the activity which provides the framework for others to follow. We do recommend that students are asked to do the research beforehand because we found this really enhanced the exercise. So while the outside class research is not compulsory it does add strength to the exercise. The contemporary nature of the exercise also maintains students' interest and enthusiasm. Creativity is encouraged but the semi-structured nature of the exercise ensures a good tie-in with the course content. We would caution the use of active learning without a direct tie-in with the course content as this while breaking the monotony of traditional lectures, would not add to the students' learning. Active learning enhances student learning when carefully crafted, engrosses the student in learning and fosters a more positive interactive learning environment. 


\section{REFERENCES}

1. Browne, Rachel (2008), Turning water into wine, The Sun Herald, 3 August.

2. Dacko, S.G. (2001) "Narrowing skill development gaps in marketing and MBA programs: The role of innovative technologies for distance learning," Journal of Marketing Education, Vol. 23, No. 3, p.228-239.

3. Elam, E.L.R. and Spotts, H.E. (2004) "Achieving marketing curriculum integration: A live case study approach," Journal of Marketing Education, Vol. 26, No. 1 p.50-65.

4. Gremler, D.D., Hoffman, K.D., Keaveney, S.M. and Wright, L.K. (2000) "Experiential Learning Exercises in Services Marketing Courses," Journal of Marketing Education, Vol. 22, No. 1 p.35-44.

5. Granitz, N. A. (2001) "Active Learning and morality: incorporating greater meaning into marketing education," Marketing Education Review, Vol. 11, No. 2.

6. Hamer, L.O. (2000) "The Additive Effects of Semistructured Classroom Activities on Student Learning: An Application of Classroom-Based Experiential Learning Techniques," Journal of Marketing Education, Vol. 22, No. 1, p.25-34.

7. Jakubowski, L.M., (2003) "Beyond Book Learning: Cultivating the Pedagogy of Experience Through Field Trips," The Journal of Experiential Education, Vol. 26, No.1.

8. Kennedy, E.J., Lawton, L. and Walker, E. (2001) "The case for using live cases: Shifting the paradigm in marketing Education" Journal of Marketing Education, Vol. 23, No. 2, p.145-151.

9. McConnell, D.A., Steer, D.N. and Owens, K.D. (2003 "Assessment and Active Learning Strategies for Introductory geology Courses," Journal of Geoscience Education, Vol. 51, No. 2, p.205-216.

10. Pearce, G. \& Sutton-Brady, C. (2003) "International Business Theatre (IBT): An alternative assessment method for enhancing student learning in International Marketing," Assessment \& Evaluation in Higher Education, Vol. 28, No.1, pp.3-15.

11. Razzouk, N.Y., Seitz, V. and Rizkallah, E. (2003) "Learning by doing: Using experiential projects in the undergraduate marketing strategy course," Marketing Education Review, Vol. 13 No. 2.

12. Smith, L.W. and Van Doren, D.C. (2004) "The reality-based learning method: A simple method for keeping teaching activities relevant and effective," Journal of Marketing Education, Vol. 26, No. 1 p. 6674.

13. Sutton-Brady, C. (2006) "Innovation in Assessment: Injecting Reality into Business Education," Journal of College Teaching and Learning, Vol.3, No.10.

14. Tabor, S.W. (2005) "Achieving significant learning in E-Commerce education through small business consulting projects," Journal of Information Systems Education, Vol.16, No. 1.

15. Young, M.R. (2002) "Experiential Learning=Hands-On+Mind-On” Marketing Education Review, Vol. 12 No. 1.

16. Zych, J.M. (1997) “Adding case materials to reinforce the realism in marketing simulations," Marketing Education Review, Vol. 7, No. 2.

17. http://www.mecho.com.au/lifestyle/drinks/voss-artesian-bottle-water-norway-luxury

18. http://www.blingh2o.com

19. http://www.lovelimitededition.com

20. http://www.vosswater.com

21. http://www.blingh2o.com

22. http://www.lagrandeepicerie.fr 
NOTES 